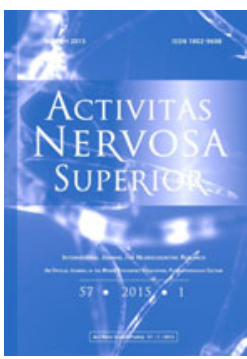

\title{
Journal
}

ANS: Journal for Neurocognitive Research Homepage:

www.activitas.org

SHORT COMMUNICATION

\section{Behavioral AtTITUdeS IN DifFERENT CUltures: RUSSIAN-SPEAKING NEW COMERS VS. NATIVE ISRAEL CITIZENS}

\author{
Vadim S. Rotenberg, ${ }^{*}{ }^{1,2}$ Paul Gurwitz, ${ }^{1}$ Alexander Cholostoy ${ }^{1}$ \\ ${ }^{1}$ Abarbanel Mental Health Center, Bat-Yam, Israel \\ ${ }_{2}^{2}$ Tel-Aviv University, Tel-Aviv, Israel
}

\begin{abstract}
Groups of Russian-speaking and native Israel citizens (adults and adolescents) were compared according to their behavioral attitudes by using the BASE test - a projective questionnaire for the estimation of behavioral attitudes (search activity, stereotyped activity, chaotic activity and renunciation of search). Native citizens, girls and adult women, displayed a lower level of stereotyped activity and a higher level of chaotic activity in comparison to their Russian-speaking peers. The ratio between search activity and stereotyped activity was higher in native citizens. Authors propose that the difference between groups is determined by the difference in the traditions of growing up in Israel and in former USSR: the conditions for growing up are more free and with less pressure and requirements towards children in Israel. It can decrease an attitude towards the stereotyped behavior and increase not only the tendency towards search activity but also toward chaotic activity thus increasing the longevity of maturation.
\end{abstract}

Key words: Behavioral Attitudes; Maturation; Search activity; Stereotyped activity

\section{INTRODUCTION}

Search activity concept (Rotenberg, 1984; 2009; Rotenberg \& Arshavsky, 1979; Rotenberg \& Boucsein, 1993) proposed the discrimination between the four different types of behavior: 1 . Search activity (SA) which is designed to change the actual situation or the subject's attitude to it with uncertainty regarding the results of this activity, but with constant monitoring of the results at all stages of activity; 2. Stereotyped behavior (St) which uses habitual skills and algorithms with highly predictable results. This type of behavior is relevant and adaptive in the definite conditions regulated by strong rules and restrictions. 3. Chaotic or panick behavior (Ch) which may seem to imitate SA but does not include the monitoring of the results of the activity and for this reason it cannot use the results in order to improve the direction of activity; It is fraught with inadequate actions and often finally leads to renunciation of search (giving up); 4 . Renunciation of search (passive behavior, Pa) that manifests itself in giving up, helplessness and freezing.

In our previous investigations performed on healthy Russian-speaking new comers in Israel we have shown that SA and St (adaptive goal-directed forms of behavior) have positive meaning and in women SA and St were almost equal $(2.84, \mathrm{SD}=2.63$ vs. $2.53, \mathrm{SD}=2.33)$ while

*Vadim Rotenberg, email: vadir@post.tau.ac.il

Received February 21, 2015; accepted March 1, 2015; Act Nerv Super 57(1), 29-33; ISSN-1802-9698 
in men SA displayed a tendency to be higher than $\mathrm{St}(4.444, \mathrm{SD}=2.22$ vs. $2.31, \mathrm{SD}=2.20)$. Maladaptive forms of behavior ( $\mathrm{Ch}$ and $\mathrm{Pa}$ ) have usually negative meanings in both genders (Rotenberg et al., 2001). This regularity was especially prominent in the group of those new comers who became perfectly adapted to the new environment in the first few years in Israel, already passed the crisis of emigration and demonstrated a low level of distress during investigation. Most of them were employed according to their level of education.

In those subjects of both genders who have been still in the crisis of adaptation to the new environment the level of Ch displayed a nonsignificant tendency to be higher, in comparison to those who passed crisis, and in healthy women who found a job that does not correspond to their education and is less respective, the level of St was significantly smaller.

The high level of distress related to the process of adaptation in men was accompanied by the non-significant increase of $\mathrm{Ch}$ and in women by the non-significant increase of $\mathrm{Pa}$. In our previous investigation we have shown (Rotenberg \& Zusman, 2002) that in men who are employed not according to the level of their education regular psychotherapy oriented on the restoration of subject's self-esteem, on the increase of the motivation of achievement and on the improvement of behavioral attitudes increases SA and decreases $\mathrm{Ch}$ and $\mathrm{Pa}$, while in women it has a tendency to increase SA and Ch.

Our investigation of the healthy Russian-speaking adolescents (Rotenberg et al., 1998), who are successfully studying in school and belong to the well-adjusted families have shown that SA has a tendency to increase from age 10-12 to age 13-15 years, especially in boys, while other behavioral attitudes demonstrated a trend toward the decrease with age. Chaotic behavior, especially in boys, decreased with age significantly. It was a sign of maturation.

SA was higher in adolescents of both genders when the level of distress was low, in comparison to the increased level of distress.

The well-adjusted adolescents in age between 16-18 years, who were successfully studying in school displayed almost the same level of the BASE scales (Venger et al., 1996) as the welladjusted adolescents in age between 13-15 years (Rotenberg et al., 1998). At the same time adolescents with adjustment disorders displayed a significant decrease of SA as well as significant increase in $\mathrm{Ch}$ and $\mathrm{Pa}$ (Venger et al., 1996), in comparison to the well adjusted adolescents.

Thus, we have discovered some regularities in the dynamic of behavioral attitudes dependent on age, gender and on the level of adaptation to the environment. However all these findings were based on the investigations of the selected group - Russian-speaking new comers in Israel. It was unknown whether the similar regularities characterize other groups of population - for instance, Israel native citizens, who are culturally different from our selected group.

\section{METHOD}

The task of the present investigation was to check this topic and to compare attitudes towards the different types of behavior in Russian-speaking Israel citizens and in the Israel native citizens. Subjects were 25 healthy Russian-speaking adults Group I) (10 men and 15 women) in mean age 36 years and 37 healthy native Israel citizens (Group II) (17 men and 20 women) in mean age 34.8 years. The mean age of Russian speaking men was 43.5 years, in Russian speaking women 31 years. The mean age of the native citizens in men was 37 years, in women 33 years.

In addition, we have included in this investigation data that we have got together with D. Stein and Y. Nachum on 32 girls in age 13-18 born in Israel and we have compared this group with 2 groups of Russian-speaking girls (new comers in Israel) in age 10-12 years and 13-15 years that have been investigated previously (Rotenberg et al., 1998).

Subjects were asked to complete BASE test (Venger et al., 1996)- a projective questionnaire for the estimation of behavioral attitudes. It includes descriptions of 16 open situations with 
four possible reactions on each of them. The test subject has to choose two types of behavior in each situation: the most appropriate from his/her point of view (scored by a sign + ) and the less appropriate (scored by a sign --). The preferences of the subject provide an opportunity for quantitative measurements of each of the above mentioned behavioral attitudes: SA, St, $\mathrm{Ch}, \mathrm{Pa}$. The total score of the four scales can range from -16 to +16 .

All reactions on test situations seem equally acceptable both ethically and pragmatically. The subject is predicted that every choice is legitimate.

Here is the example to illustrate the general principle: "A group of hikers went to a cavern unfamiliar to them. Just as they arrived inside the cavern, a landslide buried the exit. While discussing the situation, the following suggestions arose:

A. I suggest searching for another exit. We'll mark our way with small mounds of stones so that we might recognize the place we would once pass even by touch when our flashes are out.

B. Of course, we must search for another exit! But we cannot waste our time for excessive precautions. Remember that we do not have enough food.

C. Let us wait till our friends find us. If we economize our strength, so our poor provision will be enough to maintain our life while waiting.

D. I suggest trying to dig a passage through the landscape. This can take a lot of time and efforts, but at least we know that the exit is here and don't know whether there is another exit elsewhere."

E. In this situation, the answer " $\mathrm{A}$ " corresponds to search activity because it suggests activity with an unpredictable outcome, and fixation of all intermediate results (marking the way with stones). The answer " $\mathrm{B}$ " indicates chaotic activity because it denies fixation of the intermediate results and emphasizes the urgency of the required activity. The answer " $\mathrm{C}$ " reflects passive attitudes because it does not suggest any types of activity. The answer " $\mathrm{D}$ " shows a tendency to stereotyped behavior: high level of activity in the same direction without considering real obstacles.

\section{RESULTS}

\subsection{Behavioral attitudes in healthy adolescents (new comers vs. Israel native citizens)}

As it was shown in our previous investigation (Rotenberg et al., 1998), Russian-speaking girls from the families that recently immigrated to Israel from the former USSR (with mean duration of residence in Israel of 5.7 years) displayed a non-significant tendency to the increase of SA and to the decrease of Ch from age 10-12 years to age 13-15 years. Although girls- native Israel citizens were older than the oldest Russian-speaking group (13-18 years vs. 13-15 years) they displayed a lower level of $\mathrm{SA}(2.19, \mathrm{SD}=2.83$ vs. $4.22, \mathrm{SD}=2.7, \mathrm{p}=0.004)$, a lower level of $\mathrm{St}(0.59, \mathrm{SD}=2.59$ vs. $2.26, \mathrm{SD}=3.49, \mathrm{p}=0.02)$ and a higher level of $\mathrm{Ch}(1.03$, $\mathrm{SD}=1.92$ vs. $-1.87, \mathrm{SD}=3.35, \mathrm{p}=0.0002)$.

In native citizens the level of St was lower and the level of Ch was higher also in comparison to the maladjusted Russian- speaking adolescents (boys and girls of the same age) while in comparison to this group the level of SA was higher and the level of Pa was lower in girls born in Israel. SA and St belong to adaptive while $\mathrm{Ch}$ and $\mathrm{Pa}$ to maladaptive behavior attitudes thus our data show that healthy girls, native citizens of Israel, according to most behavioral attitudes (except of $\mathrm{Pa}$ ) are less matured than their Russian-speaking peers and according to some behavioral attitudes (chaotic activity) are even less adapted than Russianspeaking adolescents with definite adjustment disorders.

\subsection{Behavioral attitudes in adults (new comers vs. Israel native citizens)}

The similar difference was shown in adults. Russian speaking women displayed significantly higher level of St $(2.8, \mathrm{SD}=2.83$ vs. $-0.8, \mathrm{SD}=2.5, \mathrm{p}=0.0002)$ and lower level of $\mathrm{Ch}(--4.7, \mathrm{SD}=3.49$ vs. $0.4, \mathrm{SD}=2.13, \mathrm{p}=0.0002)$ in comparison to women, native citizens of Israel. At the same time 
Russian-speaking females demonstrated a non-significant increase in $\mathrm{Pa}(--1.53$ vs. -2.65$)$. The level of SA was almost similar in both groups (3.4 vs. 3.05), however the ratio SA/St was significantly higher in Israel native citizens (3.81 vs. 1.21).

The difference in the same direction was shown in men however this difference does not achieve the level of significance. In Russian-speaking men Ch displayed a tendency to be lower (--1.6 vs. 0.05$)$ and St to be higher (2.5 vs. 1.8), in both cases $p>0.05$.

\section{DISCUSSION}

According to the presented data, the difference in behavioral attitudes between native Israel citizens and Russian-speaking new comers is at least partially gender related and in women has a similar direction in different ages: in native citizens, in girls and in adult women, the tendency towards stereotyped behavior is lower and the tendency towards chaotic behavior is higher than in Russian-speaking new comers- girls and women. Unfortunately in the present investigation we have no data according to native citizens-boys, however men in the compared groups display a similar although statistically not significant difference.

What is the reason of such difference between groups? The first possibility is that it is caused by the stress of adaptation in new comers that requires the mobilization of all coping resources, determines the activation of the adaptive behavioral attitudes and blocks the maladaptive chaotic behavior. We cannot totally exclude such possibility, however some our data do not confirm this proposition.

The members of both native citizens and new comers in this investigation have been in general adjusted to the environment (most of them were working according to the level of education or studying at a University). This is also partially confirmed by the level of SA/St ratio in men and women in both groups. In our previous investigation (Rotenberg et al., 2001) we have shown that healthy Russian-speaking new comers (and especially Russian-speaking men), who are in a state of the high distress caused by the crisis of adaptation to the new environment display higher SA/St ratio in comparison to those who already passed the crisis of adaptation, and we considered it as a mobilized mechanism of adaptation to this crisis. In the present investigation the SA/St ratio is equally low in men in both groups; it is relatively increased only in women- native citizens and thus contradicts our hypothesis showing that the highly adaptive type of behavior- search activity- is prominent in native citizens, not only in new comers.

Another possible explanation is the difference between populations in cultural variables and in traditions of the growing up and education. The free and unrestricted behavior of Israel children from the pre-school period and during the school education is opposite to the experience of children in the former USSR.

The demands to children in the former USSR society were higher than in Israel. They were trained from early age, and trained in a very persistent way, to follow definite and restricted rules, to accept discipline, to study in school hard. This last attitude was especially strong in Jewish families. Such demands stimulated the development of particular behavioral attitudes like stereotyped activity and suppressed chaotic behavior. The style of growing up and teaching in Israel is very different (and similar to those in USA, but even exaggerated): the child has an opportunity to develop free and to be pleased with the conditions of growing up and education. Such approach has of course some positive outcomes: children are not under the continuous pressure, they display a more spontaneous behavior (including also search behavior), they are not in the state of fear toward the surrounding environment and possible failures, they have more easy relationships with adults. Probably such growing up reduces the tendency towards giving up (passive behavior) in stressful situations.

However, this way of growing up and education oriented on the pleasure does not take into consideration that the highest pleasure of the developing subject is the pleasure of achievement that includes also the experience of overcoming obstacles. Children do not know 
initially that it is the highest pleasure and are not going spontaneously to confront obstacles and have to be trained to adopt these skills and to get a positive experience from using them. From this reason, the education has to include also some strong rules, red lines and definite demands combined with the stimulation of efforts and encouragement of the self-organization of behavior.

In addition, definite rules and restrictions that suppress tendency toward the chaotic behavior are important for the formation of the relevant social interrelationships, especially in the unfamiliar conditions and with unfamiliar persons, while the atmosphere in the classroom where every subject is free in his/her behavior prevents the restriction of chaotic behavior and delays the personal maturation.

Thus, the Israel style of growing up and education has its advantages and disadvantages, and the present investigation shows that the disadvantages may be serious, with the long lasting consequences up to the adulthood.

Why the difference between groups is more prominent in women? Up to now we have no definite answer to this question. First of all it is necessary to increase the investigated groups and include native citizens and new comers boys in a different age, including boys before army service and just after it. Probably the service in army determines this difference. Of course, in Israel girls are also passing army, however the conditions of the army service and the level of difficulties subject has to pass are different in girls and boys, especially if boys are going to fighting attachments. We cannot exclude that such experience helps boys to develop a more adult type of behavior (although the tendency in behavioral attitudes in men is similar to those in women).

\section{REFERENCES}

Rotenberg V.S. (1984) Search activity in the context of psychosomatic disturbances, of brain monoamines and REM sleep function. Pavlovian Journal of Biological Science, 19, 1-15.

Rotenberg V.S. (2009). Search Activity Concept: Relationship between behavior, health and brain functions. Activitas Nervosa Superior, 51, 12-44

Rotenberg V.S., \& Arshavsky V.V. (1979) Search activity and its impact on experimental and clinical pathology. Activitas Nervosa Superior, 21, 105-115.

Rotenberg V.S., \& Boucsein W. (1993). Adaptive versus maladaptive emotional tension. Genetic, Social and General Psychology Monographs, 119, 207-232.

Rotenberg V.S., Kutsay S., \& Venger A. (1998). Behavioral attitudes and distress in adolescents: Relationships to age and gender. Homeostasis in Health and Disease, 39, 57-64.

Rotenberg V.S., Zusman Y. (2002). The dynamics of behavioral attitudes in the process of group therapy. Dynamische Psychiatrie/Dynamic Psychiatry, 35, 390-400.

Rotenberg V.S., Kutsay S., \& Venger A. (2001). Behavioral attitudes and the level of distress in the process of adaptation to the new society. Stress Medicine, 17, 177-183.

Venger A., Rotenberg V.S., \& Desiatnikov Y. (1996). Evaluation of search activity and other behavioral attitudes in indefinite situations. Dynamische Psychiatrie/ Dynamic Psychiatry, 160/161, 368-377. 